\title{
Dosage Schedule for Antipyretic Combination Formulations: Experts' Reply I
}

\author{
Sunil Gomber • Manish Saxena
}

Received: 15 April 2013 / Accepted: 16 April 2013 /Published online: 11 June 2013

(C) Dr. K C Chaudhuri Foundation 2013

To the Editor: Paracetamol (acetaminophen) as an antipyretic is available as a single drug as well as in combination with other NSAIDs like ibuprofen, mefenemic acid etc. We are trying to find out rationale of such combination, the dosage and frequency of such combination if they are to be used and whether of such combination leads to any interactions.

\section{ACETAMINOPHEN (Drug A) with IBUPROFEN (Drug B)}

Both of above drugs have same mechanism of action by decreasing prostaglandin synthesis in CNS. There are no significant interactions between the two drugs [1]. There are pharmacokinetic differences between the two [2]:

\begin{tabular}{lcc}
\hline & Drug A & Drug B \\
\hline Onset of action & $10-60 \mathrm{~min}$ & $<1$ y: $69 \pm 22 \mathrm{~min} ;>$ \\
Duration of action & $4-6 \mathrm{~h}$ & $\begin{array}{c}6: 109 \pm 64 \mathrm{~min} \\
6-8 \mathrm{~h}\end{array}$ \\
\hline
\end{tabular}

Thus therapeutic effect of $(\mathrm{A}+\mathrm{B})$ is equal to $\mathrm{A}$ or $\mathrm{B}$ as there are no interactions between the two drugs and both have same mechanism of action. The only advantage this combination offers against the two drugs individually is early onset of action by virtue of drug $A$ and prolonged action by virtue of drug $B$. If the combination is anyways chosen the dosage of such combination can be calculated on basis of any one constituent as the preparation available in

S. Gomber $(\bowtie) \cdot$ M. Saxena

Department of Pediatrics, UCMS \& GTB Hospital

Delhi 110095, India

e-mail: sunilgomber@hotmail.com market have both drugs in same strength as their single drug preparation. Frequency can be judged on basis of drug with longer duration of action.

\section{ACETAMINOPHEN (Drug A) with MEFENEMIC ACID (Drug B)}

Mefenemic acid is also an NSAID which is primarily used as short term relief of mild to moderate pain including primary dysmenorrhoea [1]. It is not a preferred antipyretic [3, 4], also its use is not recommended in children and pregnant women [1]. Thus its combination with acetaminophen as an antipyretic is not justified.

The two drugs namely ibuprofen and mefenemic acid do have significant side effects [1] and as such Acetaminophen is preferred antipyretic [4]. The combination of these drugs does not offer much but increases the chances of adverse effects, thus acetaminophen along with tepid sponging seems to be more prudent way for antipyresis.

\section{References}

1. Grosser T, Smyth E, Fitzgerald GA. Anti-inflammatory antipyretic and analgesic agents; Pharmacotherapy of gout. In: Brunton LL, Chabner BA, Knollman BC, eds. Goodman and Gillman Pharmacological Basis of Therapeutics. 12th ed. New York: McGraw Hill; 2011. pp. 982-4; 987-9.

2. Taketomo CK, Hodding JH, Krauss DM. Lexi-comp's Pediatric Dosage Handbook International. 1997;13e: pp. 39-42; 723-7.

3. Balasubramanian S, Sumanth A. Mefenamic acid-role as antipyretic. Indian Pediatr. 2010;47:453.

4. Chandra J, Bhatnagar SK. Antipyretics in children. Indian J Pediatr. 2002;69:69-74. 